\title{
New drugs to treat tuberculosis
}

\author{
Susan Swindells
}

Address: University of Nebraska Medical Center, 988106 Nebraska Medical Center, Omaha, NE 68198-8106, USA

Email: sswindells@unmc.edu

Fl000 Medicine Reports 2012, 4:12 (doi:10.3410/M4-12)

This is an open-access article distributed under the terms of the Creative Commons Attribution-Non Commercial License (http://creativecommons.org/licenses/by-nc/3.0/legalcode), which permits unrestricted use, distribution, and reproduction in any medium, provided the original work is properly cited. You may not use this work for commercial purposes.

The electronic version of this article is the complete one and can be found at: http://f $1000 . c o m / r e p o r t s / m / 4 / 12$

\begin{abstract}
Tuberculosis (TB) has been a leading cause of death for more than a century. While effective therapies exist, treatment is long and cumbersome. Tuberculosis control is complicated by the overlapping problems created by global inadequacy of public health infrastructures, the interaction of the TB and human immunodeficiency virus epidemics, and the emergence of drug-resistant TB. After a long period of neglect, there is now significant progress in development of TB diagnostics and therapeutics. Focusing on treatment for active TB, we review the new pathways to TB regimen development, and the new and repurposed anti-TB agents in clinical development.
\end{abstract}

\section{Introduction}

In 2010, the World Health Organization (WHO) reported 8.8 million incident cases of TB, 1.1 million deaths from $\mathrm{TB}$ among HIV-negative people and an additional 0.35 million deaths from HIV-associated TB [1]. TB is the fourth leading infectious killer of adults worldwide, the third largest killer of women in their reproductive years, and the leading infectious cause of death among people with HIV/AIDS [2-4]. In recent years, the world has seen a rapidly emerging epidemic of drug-resistant $\mathrm{TB}$, multidrug-resistant $\mathrm{TB}$, and extensively drug-resistant $\mathrm{TB}$, which is highly lethal and extremely expensive and complicated to treat [5].

Despite these sobering facts, the current first-line fourdrug regimen for drug-susceptible TB is nearly 50 years old, takes six to nine months to complete and has significant side effects. Treatment for drug-resistant TB may take up to 30 months [6]. Even though more than 250,000 children develop TB each year, inexcusably, most anti-TB agents are not available in suitable pediatric formulations [7]. While liquid formulations may be easy to administer to young children, they are bulky, more expensive, and some have unacceptable toxicity, for example isoniazid syrup, which is in a sorbitol-based solution and causes diarrhea. Only recently have TB drug-dosing recommendations been revised to reflect differences in the way children metabolize drugs and, until recently, most first-line drugs were grossly underdosed [8]. Equally importantly, the last time a new drug for TB treatment was licensed was 1998 (rifapentine) (Figure 1). There is urgent need for more effective and tolerable treatment of drug-susceptible and drugresistant disease, latent TB infection, and dosing strategies for children. Regimens that can be safely co-administered with antiretroviral therapy are also needed for the growing number of patients co-infected with both HIV and TB.

Finally, after a long drought, new drugs are available and new strategies for treatment of latent disease and for regimen development in active disease are emerging. There is renewed interest in the rifamycin class of drugs. Shorter courses of treatment for latent TB look promising; in addition, studies in the mouse model suggest that higher doses of rifampin or rifapentine may markedly improve the treatment of drug-susceptible disease $[9,10]$. Fluoroquinolones may allow shorter treatment durations for drug-susceptible disease, though initial phase IIB trials have shown inconsistent results [11]. Discussed in more detail below, there are six novel drugs in four new classes in clinical trials, including TMC207, OPC67683, PA824, SQ109, PNU-100480 and AZD5847. These agents are anticipated to dramatically shorten and otherwise improve the treatment of drug-resistant, and 


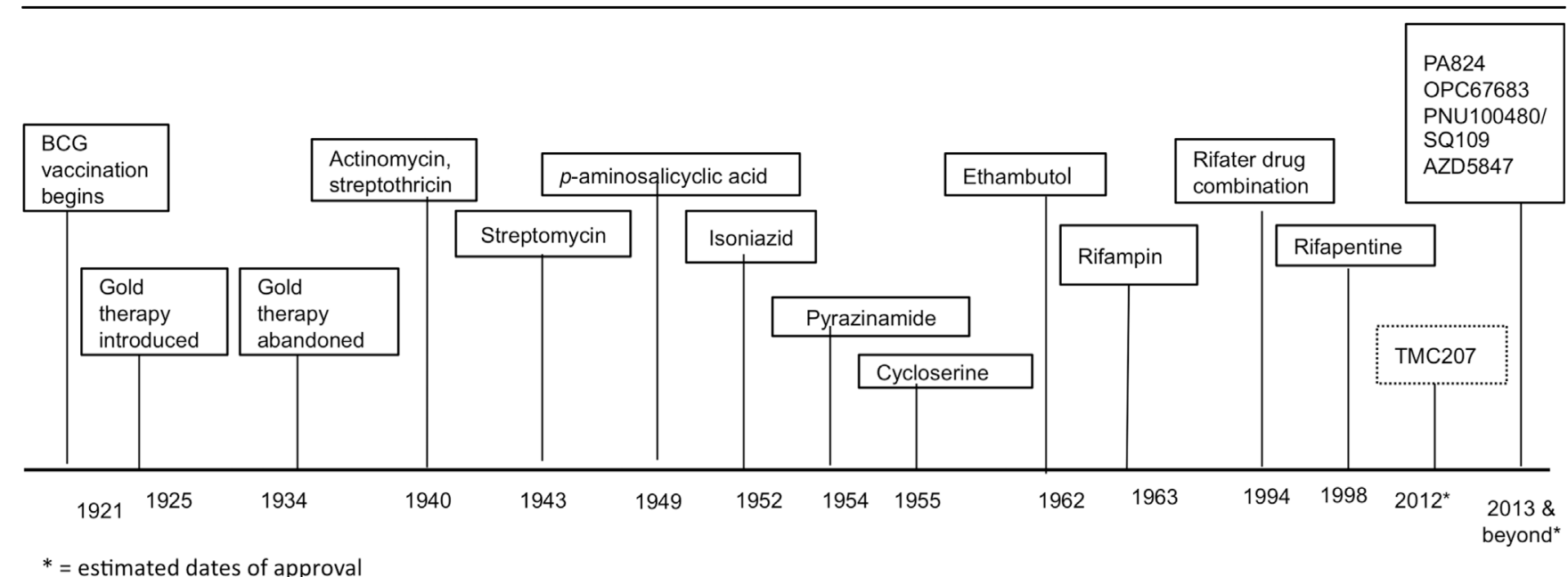

\section{TIMELINE FOR TB DRUG DEVELOPMENT}

Major milestones in TB treatment over the last century are outlined by the date of approval of the drug or intervention. Approval dates for drugs in development are estimated.

possibly drug-susceptible, tuberculosis - used either separately or in novel combinations.

Just as important as the new drugs are the emerging new strategies for TB treatment regimen development, and regulatory changes to expedite this. Since the 1950s, TB clinical trials have consisted of addition to, or substitution from, an existing drug in a standard regimen. Traditional trial designs use cure without relapse as an endpoint, which requires at least 6 months of treatment and then 12-18 months of follow-up. Therefore, large Phase III trials often take five or six years to complete, and with multiple compounds now in the pipeline, development of a novel regimen using this model would literally take decades. Thankfully, however, the recent increase in global philanthropy directed at $\mathrm{TB}$ and the unprecedented collaboration amongst major stakeholders have created opportunities to overcome bottlenecks and dramatically shorten the time to regimen development. An excellent example of such a collaborative initiative is the Critical Path to TB Drug Regimens (CPTR) [12]. Including researchers, drug developers, regulatory agencies and donors, the goal of this program is to address the scientific, clinical, regulatory and legal challenges posed by development of novel drug combinations. The first clinical trial of multiple novel agents in an early bactericidal activity study was recently presented ([13], discussed further below) and several more are in development. Treatment shortening is also an important goal for the near future, as is the development of more tolerable regimens. Suitable formulations and regimens for children are urgently needed. So-called "universal regimens" with activity against drug-sensitive and multi-drug resistant/extensively drug-resistant TB are under discussion. Future goals in TB drug development also include identification of relevant biomarkers to act as surrogate endpoints, rather than waiting for relapse-free survival [14].

\section{New applications of existing drugs Rifamycins}

Rifampicin is a cornerstone of TB treatment, largely due to its sterilizing ability (i.e. the ability to kill dormant, less active, as well as rapidly dividing, mycobacteria). Surprisingly, the daily dose of $600 \mathrm{mg}$ currently used is likely not on the optimal part of the dose-response curve, and higher doses may be needed to achieve treatmentshortening goals for drug-sensitive TB [15]. Sterilizing activity increases with escalating doses in the mouse model, which is often used in TB drug development and has proved an excellent predictor of clinical trial results in humans [9]. One possible problem with this is that older studies suggested poor tolerability with weekly 
dosing of rifampin at higher doses, including hypersensitivity reactions with "flu-like" symptoms, thrombocytopenia, hemolytic anemia, and renal failure [16]. However, this may not be the case with daily dosing, and high-dose rifampicin is under study, for example in the Rifaquin study which will evaluate high dose rifampin and gatifloxacin (http://rifaquin.wordpress.com/); the HIGHRIF project which is a series of 4 trials of high dose rifampicin (http://www.edctp.org); and an NIHsupported study in Brazil and Peru (http://clinicaltrials. gov/ct2/show/NCT01408914).

For HIV-infected patients requiring protease inhibitorbased therapy, rifabutin is generally recommended where available because of reduced potential for significant drug-drug interactions. A recent review of the scientific literature found that rifabutin is effective and safe in this setting [17].

From the same class, but with a longer half-life, rifapentine is being evaluated for both latent and active TB. In an 8,000 patient, international study of latent infection from the TB Trials Consortium (TBTC) funded by the Centers for Disease Control and Prevention (CDC), weekly rifapentine at $900 \mathrm{mg}$ with isoniazid $900 \mathrm{mg}$ weekly for 3 months was not inferior to the standard 9 month isoniazid regimen recommended for latent TB infection treatment in the US [18]. The CDC guidelines were revised in 2011 to include this regimen [19]. An even shorter regimen of rifapentine and isoniazid for one month in HIV co-infected patients is under study by the AIDS Clinical Trials Group, and Phase III trials with rifapentine for pulmonary $\mathrm{TB}$ are ongoing. Somewhat surprisingly, the Tuberculosis Trials Consortium Study 29 found similar rates of sputum culture conversion (i.e. from positive to negative for $\mathrm{TB}$ ) at eight weeks in 381 smear-positive patients with $\mathrm{TB}$ using rifampin or rifapentine [20].

Unfortunately, all rifamycins induce phase II and P450 metabolizing enzymes, resulting in significant drugdrug interactions when used with antiretroviral agents. This presents a major obstacle in treatment of HIV/TB co-infected patients with rifamycins, particularly those who require protease inhibitor therapy [21]. Rifapentine was previously considered a less potent inducer of the metabolizing CYP3A isozyme than rifampin, and therefore less likely to cause significant drug-drug interactions when used with antiretroviral agents. However, recent data in healthy volunteers at clinically relevant doses using midazolam as a probe found rifapentine to be a more potent inducer of CYP3A than rifampin [22].

\section{Fluoroquinolones}

Although not licensed for TB treatment, the broad spectrum antibiotics fluroquinolones are often used in the treatment of drug-resistant TB and are also under study as first-line agents. Levofloxacin, moxifloxacin, and gatifloxacin are all active in vitro and in a mouse model, resulting in the ability to shorten treatment to 4 months [23]. Phase II trial results with fluroquinolones have been inconsistent, but larger ongoing studies will better define the contribution of this class of drugs.

A Phase II study of three fluroquinolones in 217 patients with pulmonary tuberculosis demonstrated that gatifloxacin and moxifloxacin (but not ofloxacin) improved the sterilizing activity of regimens used [24]. Moxifloxacin has also been shown to improve sputum culture conversion in the initial phase of tuberculosis treatment when compared to ethambutol in a phase II trial [25]. In a similar study, the addition of moxifloxacin did not affect two-month sputum culture status but did show increased activity at earlier time points [26]. Substitution of moxifloxacin for isoniazid resulted in a small but statistically insignificant increase in Week 8 sputum culture negativity in TBTC Study 28 [27]. In addition, a recent observational study evaluated the effectiveness of standardized regimens for patients with proven multidrug-resistant tuberculosis previously untreated with second-line drugs in lowincome countries. The authors found that a regimen of a minimum of nine months of treatment with gatifloxacin, clofazimine, ethambutol, and pyrazinamide supplemented by prothionamide, kanamycin, and high-dose isoniazid during an intensive phase of a minimum of four months resulted in treatment outcomes comparable to those obtained with first-line treatment [28].

Fluoroquinolones do not have significant drug-drug interactions with antiretroviral drugs, although adverse effects limit utility in children and pregnant women. Moxifloxacin may also have overlapping toxicity with regard to prolongation of the QT interval. Several studies of fluoroquinolones are ongoing. The Global Alliance for TB Drug Development (http://www.tballiance.org) is conducting a large, multicountry phase III trial using moxifloxacin in a four-month regimen. Availability of gatifloxacin is limited at present but levofloxacin is under study in multi-drug resistant TB.

\section{New drugs \\ TMC207}

TMC207 (bedaquiline) is a diarylquinoline with a novel mechanism of action by inhibiting mycobacterial ATP synthase [29]. It has potent activity against Mycobacterium tuberculosis isolates regardless of resistance, but little 
activity against other common bacterial pathogens. Used alone in the mouse model, TMC207 was more active than conventional multidrug therapy combined, and produced complete sterilization at 2 months in combination therapy [29]. In a pivotal phase II trial in patients with multi-drug resistant $\mathrm{TB}$, the drug was highly effective and reduced response time by more than half when given together with an optimized background regimen, compared to the optimized background regimen alone [30]. Sputum culture conversion at six months was $79 \%$ in the TMC207 arm and 58\% in the optimized background regimen arm [31]. Phase III trials are in development for this exciting new addition to the $\mathrm{TB}$ armamentarium and provisional FDA approval is anticipated in 2013.

Bedaquiline is being developed in an unusual partnership between the developer, Tibotec, and the Global Alliance for TB Drug Development, which is a non-profit organization. Under the terms of the agreement, Tibotec will be responsible for the worldwide development of and access to TMC207 for treatment of multidrugresistantTB. Tibotec granted the TB Alliance a royaltyfree license for the worldwide development of, and access to, TMC207 for drug-susceptible TB.

Although the drug is a substrate of the metabolizing enzyme CYP3A, problematic drug-drug interactions with antiretroviral agents are not anticipated because TMC207 is only metabolized by CYP3A, but does not induce or inhibit the enzyme. However, the drug has a very long half-life, and unanswered questions remain about longterm safety and tolerability. Concentrations of TMC207 resistant TB. Tibotec granted the TB Alliance a royaltywith rifamycins, but no significant effect was seen when given with efavirenz [32].

Despite these unknowns, TMC207 represents a major milestone in TB drug development as it will dramatically improve treatment of drug-resistant $\mathrm{TB}$, and might also be useful for treatment shortening in patients with susceptible disease and for treatment of multidrugresistant/extensively drug-resistant TB contacts, another urgent need in TB therapeutics.

\section{Nitroimidazoles: PA-824 and OPC-67683 (delamanid)}

The next generation of nitroimidazoles shows promise for TB treatment. It includes PA824, under development by the Global Alliance for $\mathrm{TB}$ Drug Development following in-licensing from Chiron. The Otsuka Pharmaceutical Company is developing a related compound, OPC-67683 (delamanid). Both are nitrofuranylamides with potent activity against drug-sensitive and drugresistant TB [33]. In mice, either drug in combination with rifampicin and pyrazinamide shortened TB treatment by at least 2 months $[34,35]$.

A recently presented study from South Africa evaluated TMC207, PA824 and pyrazinamide in an early bactericidal activity study, which measures decline in sputum colony counts per day among patients with sputum smear-positive pulmonary TB [13]. Addition of pyrazinamide to either drug significantly increased the early bactericidal activity, validating the mouse data described above. A combination of PA- 824 together with moxifloxacin and pyrazinamide in an early bactericidal activity study found that this three-drug combination was more effective than standard TB treatment (isoniazid, rifampin, pyrazinamide, ethambutol), a first-ever finding in a twoweek early bactericidal activity study [36]. These groundbreaking studies were greeted with great interest and excitement. More novel drug combination studies are in development, and the goal of a three-month treatment regimen appears more achievable. The next wave of planned trials may also use the new paradigm of a universal regimen, and enroll patients with either drugsusceptible or -resistant TB in the same study.

Otsuka have completed a phase II, randomized, doubleblind trial of OPC-67683 in multidrug-resistant TB patients receiving either $100 \mathrm{mg}$ or $200 \mathrm{mg}$ twice daily in addition to standardized second-line drugs. Results are not available at the time of this publication, but the dose going forward is $200 \mathrm{mg}$ and a phase III trial of patients with multidrug-resistant $\mathrm{TB}$ is recruiting in Eastern Europe.

A pharmacokinetic interaction study with PA824 and commonly used antiretroviral drugs is in development, and similar studies can proceed with OPC-6Z683 now that a dose has been selected.

\section{SQ109 (Sequella)}

SQ109 is an analogue of ethambutol, but ten times more active in preclinical studies [37]. In development from Sequella, in partnership with the National Institutes of Health, the drug is synergistic with isoniazid, rifampicin, and TMC207 and has activity against ethambutolresistant strains in vitro [38]. SQ109 has a dual mechanism of action: it blocks cell wall synthesis and prevents the efflux of companion drugs from macrophages. Multipledose healthy volunteer studies are completed and clinical trials are underway, including an extended early bactericidal activity study funded by the EDCTP.

\section{Oxazolidinones}

Oxazolidinones are protein synthesis inhibitors with a unique mechanism of action against TB [39]. This class 
includes linezolid, PNU100480 and AZD5847. In vitro, linezolid is effective at doses of $1-2 \mu \mathrm{g} / \mathrm{mL}$ against $90 \%$ of clinical isolates [40] and works well in a mouse model [39].

Unfortunately, long term administration of linezolid is associated with toxicities such as neuropathy and myelosuppression, but the drug has been evaluated retrospectively for treatment of drug-resistant TB with encouraging results $[41,42]$. Ongoing clinical trials are investigating linezolid in patients with multidrugresistant and extensively drug-resistant $\mathrm{TB}$.

A related oxazolidinone in development from Pfizer, PNU100480 (Sutezolid), is superior in preclinical models and phase I bactericidal activity studies [43]. Unlike linezolid, PNU100480 appears to have sterilizing activity: a key factor in successful TB treatment. Addition of the drug to a standard regimen produced a 2-log drop in bacillary burden in the mouse model [44]. A planned early bactericidal activity trial will help to better define the potential role of this drug.

A little further behind in development, AstraZeneca are developing an oxazolidinone, AZD5847. Healthy volunteer tolerability and pharmacokinetic studies were recently completed but results are not yet available. A phase II early bactericidal activity study is in development.

\section{Conclusions}

This is a time of unprecedented opportunity in the field of TB treatment. After a long drought, the pipeline for new ТВ therapeutics is flowing. Key organizations, companies and investigators are collaborating to develop new treatment paradigms for treatment of latent, drugsusceptible and drug-resistant $\mathrm{TB}$ in adults and in children. Novel combinations are being tested together rather than each drug sequentially, with the goal of dramatically shortening the time and expense associated with development of new regimens. Caution still needs to be exercised with regard to identification of resistance to the novel drugs, ensuring the optimized background regimen offers the maximum protection possible, and there remains a bottleneck between preclinical and clinical development. However, there is a global commitment to major improvements and major progress over the next decade towards a goal of eliminating TB as a global public health crisis looks likely.

\section{Abbreviations}

CDC, Centers for Disease Control and Prevention; CPTR, Critical Path to TB Drug Regimens; TB, Tuberculosis; TBTC, TB Trials Consortium; WHO, World Health Organization.

\section{Competing interests}

The author declares that she has no competing interests.

\section{References}

I. Global Tuberculosis Control 20I I [http://www.who.int/tb/publications/ global_report/en/index.html]

2. The World Health Report 2004 [http://www.who.int/whr/2004/annex/ topic/en/annex_2_en.pdf]

3. 2009 Tuberculosis and Women [http://www.who.int/tb/challenges/ gender/factsheet_womenandtb.pdf]

4. HIV and TB [http://www.cdc.gov/hiv/resources/factsheets/PDF/ hivtb.pdf]

5. Young DB, Perkins MD, Duncan K, Barry CE: Confronting the scientific obstacles to global control of tuberculosis. J Clin Invest 2008, I I 8: | 255-65.

FI000 Factor 6

Evaluated by Susan Swindells 17 May 2012

6. Matteelli A, Migliori GB, Cirillo D, Centis R, Girard E, Raviglion M: Multidrug-resistant and extensively drug-resistant Mycobacterium tuberculosis: epidemiology and control. Expert Rev Anti Infect Ther 2007, 5:857-7I.

FI000 Factor 6

Evaluated by Susan Swindells 17 May 2012

7. Swaminathan S, Rekha B: Pediatric tuberculosis: global overview and challenges. Clin Infect Dis 2010, 50(Suppl 3):SI84-94.

8. Rapid Advice: Treatment of Tuberculosis in Children [http://whqlibdoc. who.int/publications/2010/9789241500449_eng.pdf]

9. Jayaram R, Gaonkar S, Kaur P, Suresh BL, Mahesh BN, Jayashree R, Nandi V, Bharat S, Shandil RK, Kantharaj E, Balasubramanian V: Pharmacokinetics-pharmacodynamics of rifampin in an aerosol infection model of tuberculosis. Antimicrob Agents Chemother 2003, 47:2118-24.

FI000 Factor 6

Evaluated by Susan Swindells 17 May 2012

10. Rosenthal IM, Zhang M, Williams KN, Peloquin CA, Tyagi S, Vernon AA, Bishai WR, Chaisson RE, Grosset JH, Nuermberger EL: Daily dosing of rifapentine cures tuberculosis in three months or less in the murine model. PLoS Med 2007, 4:e344.

FI000 Factor 6

Evaluated by Susan Swindells 17 May 2012

II. Burman WJ: Rip Van Winkle wakes up: development of tuberculosis treatment in the 2 Ist century. Clin Infect Dis 2010, 50(Suppl 3):SI65-72.

FI000 Factor 6

Evaluated by Susan Swindells 17 May 2012

12. Critical Path to TB Drug Regimens (CPTR) [http://www.c-path.org/ CPTR.cfm]

13. Diacon A, Dawson R, Van Niekerk C, Eroundu N, Ginsberg A: Pyrazinamide increases the early bactericidal activity of TMC207 and PA-824 in patients with newly diagnosed, smear-positive pulmonary tuberculosis [abstract]. Presented at $5 \mathrm{Ist}$ Interscience Conference on Antimicrobial Agents and Chemotherapy: I7-20 September, 20I I; Chicago, IL.

14. Nahid P, Saukkonen J, Mac Kenzie WR, Johnson JL, Phillips PPJ, Andersen J, Bliven-Sizemore E, Belisle JT, Boom WH, Luetkemeyer A, Campbell TB, Eisenach KD, Hafner R, Lennox JL, Makhene M, Swindells S, Villarino ME, Weiner M, Benson C, Burman W: CDC/ NIH Workshop. Tuberculosis biomarker and surrogate endpoint research roadmap. Am J Respir Crit Care Med 201I, 1 84:972-9. 
15. Peloquin C: What is the 'right' dose of rifampin? Int J Tuberc Lung Dis 2003, 7:3-5.

FI000 Factor 6

Evaluated by Susan Swindells 17 May 2012

16. Martínez E, Collazos J, Mayo J: Hypersensitivity reactions to rifampin. Pathogenetic mechanisms, clinical manifestations, management strategies, and review of the anaphylactic-like reactions. Medicine (Baltimore) 1999, 78:361-9.

FI000 Factor 6

Evaluated by Susan Swindells 17 May 2012

17. Loeliger A, Suthar AB, Ripin D, Glaziou P, O'Brien M, RenaudThery F, Crowley S, Williams B, Ridzon R, Granich R, Gilks C: Protease inhibitor-containing antiretroviral treatment and tuberculosis: can rifabutin fill the breach? Int J Tuberc Lung Dis 2012, 16:6-15.

FI000 Factor 6

Evaluated by Susan Swindells 17 May 2012

18. Sterling TR, Villarino ME, Borisov AS, Shang N, Gordin F, BlivenSizemore E, Hackman J, Hamilton CD, Menzies D, Kerrigan A, Weis SE, Weiner M, Wing D, Conde MB, Bozeman L, Horsburgh CR, Chaisson RE: Three months of rifapentine and isoniazid for latent tuberculosis infection. $N$ Engl J Med 20II, 365:2 I55-66.

\section{Changes Clinical Practice}

FI000 Factor 13

Evaluated by David Griffith 22 Dec 201I, Richard ZuWallack and Fatima Ajaz 10 Jan 2012, Anthony Harries 10 Feb 2012, Susan Swindells 17 May 2012

19. Recommendations for use of an isoniazid-rifapentine regimen with direct observation to treat latent Mycobacterium tuberculosis infection. MMWR Morb Mortal Wkly Rep 201I, 60:1650-3.

\section{Changes Clinical Practice}

FI000 Factor II

Evaluated by David Griffith 22 Dec 201I, Susan Swindells 17 May 2012

20. Dorman S, Goldberg S, Feng P, Heilig C, Stout JE, Schluger NW, Moro R, Bozeman L, Johnson JL, Muzanye G, Nahid P, Narita M, Ray S, Bates $E$, Haile B, Weiner M, Vernon AA: A phase II study of a rifapentine-containing regimen for intensive phase treatment of pulmonary tuberculosis: Preliminary results for Tuberculosis Trials Consortium Study 29. Am J Respir Crit Care Med 20II, 183:A6413.

FI000 Factor 6

Evaluated by Susan Swindells 17 May 2012

21. Haas DW, Koletar SL, Laughlin L, Kendall MA, Suckow C, Gerber JG, Zolopa AR, Bertz R, Child MJ, Hosey L, Alston-Smith B, Acosta EP: Hepatotoxicity and gastrointestinal intolerance when healthy volunteers taking rifampin add twice-daily atazanavir and ritonavir. J Acquir Immune Defic Syndr 2009, 50:290-3.

FI000 Factor 6

Evaluated by Susan Swindells 17 May 2012

22. Dooley K: CYP3A induction by rifampin and rifapentine: Which drug and dose does it best? [abstract] Presented at 4th Int Wkshp Clin Pharmacol of TB Drugs September 20II; Chicago, IL.

23. Rodríguez JC, Ruiz M, López M, Royo G: In vitro activity of moxifloxacin, levofloxacin, gatifloxacin and linezolid against Mycobacterium tuberculosis. Int J Antimicrob Agents 2002, 20:464-7.

FI000 Factor 6

Evaluated by Susan Swindells 17 May 2012

24. Rustomjee R, Lienhardt C, Kanyok T, Davies GR, Levin J, Mthiyane T, Reddy C, Sturm AW, Sirgel FA, Allen J, Coleman DJ, Fourie B, Mitchison DA: A Phase II study of the sterilising activities of ofloxacin, gatifloxacin and moxifloxacin in pulmonary tuberculosis. Int J Tuberc Lung Dis 2008, 12:128-38.

FI000 Factor 6

Evaluated by Susan Swindells 17 May 2012

25. Conde MB, Efron A, Loredo C, de Souza GRM, Graça NP, Cezar MC, Ram M, Chaudhary MA, Bishai WR, Kritski AL, Chaisson RE: Moxifloxacin versus ethambutol in the initial treatment of tuberculosis: a double-blind, randomised, controlled phase II trial. Lancet 2009, 373:1183-9.

FI000 Factor 6

Evaluated by Ric Price and Krispin Hajkowicz 05 May 2009

26. Burman WJ, Goldberg S, Johnson JL, Muzanye G, Engle M, Mosher AW, Choudhri S, Daley CL, Munsiff SS, Zhao Z, Vernon A, Chaisson RE: Moxifloxacin versus ethambutol in the first 2 months of treatment for pulmonary tuberculosis. Am J Respir Crit Care Med 2006, 174:331-8.

27. Dorman SE, Johnson JL, Goldberg S, Muzanye G, Padayatchi N, Bozeman L, Heilig CM, Bernardo J, Choudhri S, Grosset JH, Guy E, Guyadeen P, Leus MC, Maltas G, Menzies D, Nuermberger EL, Villarino M, Vernon A, Chaisson RE: Substitution of moxifloxacin for isoniazid during intensive phase treatment of pulmonary tuberculosis. Am J Respir Crit Care Med 2009, 180:273-80.

FI000 Factor 8

Evaluated by Terence Seemungal and Saeeda Mohammed 17 Aug 2009

28. van Deun A, Maug AKJ, Salim MAH, Das PK, Sarker MR, Daru P, Rieder HL: Short, highly effective, and inexpensive standardized treatment of multidrug-resistant tuberculosis. $\mathrm{Am} \mathrm{J}$ Respir Crit Care Med 2010, 182:684-92.

\section{FI000 Factor 6}

Evaluated by Susan Swindells 17 May 2012

29. Andries K, Verhasselt P, Guillemont J, Göhlmann HWH, Neefs J, Winkler $H$, van Gestel J, Timmerman P, Zhu M, Lee E, Williams P, de Chaffoy D, Huitric E, Hoffner S, Cambau E, Truffot-Pernot C, Lounis N, Jarlier V: A diarylquinoline drug active on the ATP synthase of Mycobacterium tuberculosis. Science 2005, 307: 223-7.

FI000 Factor 19

Evaluated by Matthias Maiwald 22 Dec 2004, Ken Wilson 27 Jan 2005, Wolfgang Junge 0I Feb 2005, Thomas Meier 20 Oct 2009, Susan Swindells 17 May 2012

30. Diacon AH, Pym A, Grobusch M, Patientia R, Rustomjee R, PageShipp L, Pistorius C, Krause R, Bogoshi M, Churchyard G, Venter A, Allen J, Palomino JC, de Marez T, van Heeswijk RPG, Lounis N, Meyvisch P, Verbeeck J, Parys W, de Beule K, Andries K, Mc Neeley DF: The diarylquinoline TMC207 for multidrugresistant tuberculosis. N Engl J Med 2009, 360:2397-405.

FI000 Factor 8

Evaluated by Anthony Harries 17 Jun 2009, Susan Swindells 17 May 2012

31. McNeeley DF, the TMC207 Team, Diacon AH, Pym A, Grobusch MP, Gotuzzo E, Ticona E, De los Rios J, Le Maine V: TMC-207 versus placebo plus OBT for the treatment of MDR-TB: a prospective clinical trial. [abstract] Presented at Proceedings of the 4 Ist World Conference on Lung Health of the International Union Against Tuberculosis and Lung Disease (The Union): II-I5 November 2010; Berlin, Germany.

32. Dooley KE, Park J, Swindells S, Allen R, Haas DW, Cramer Y, Aweeka F, Wiggins I, Gupta A, Lizak P, Qasba S, van Heeswijk R, Flexner C: Safety, tolerability, and pharmacokinetic interactions of the antituberculous agent TMC207 (bedaquiline) with efavirenz in healthy volunteers: AIDS Clinical Trials Group Study A5267. J Acquir Immune Defic Syndr 2012, 59:455-62.

33. Hurdle JG, Lee RB, Budha NR, Carson El, Qi J, Scherman MS, Cho SH, McNeil MR, Lenaerts AJ, Franzblau SG, Meibohm B, Lee RE: A microbiological assessment of novel nitrofuranylamides 
as anti-tuberculosis agents. I Antimicrob Chemother 2008, 62: $1037-45$

FI000 Factor 6

Evaluated by Susan Swindells 17 May 2012

34. Matsumoto $M$, Hashizume $H$, Tomishige $T$, Kawasaki $M$, Tsubouchi $H$, Sasaki H, Shimokawa Y, Komatsu M: OPC-67683, a nitro-dihydroimidazooxazole derivative with promising action against tuberculosis in vitro and in mice. PLoS Med 2006, 3:e466.

35. Tasneen R, Tyagi S, Williams K, Grosset J, Nuermberger E: Enhanced bactericidal activity of rifampin and/or pyrazinamide when combined with PA-824 in a murine model of tuberculosis. Antimicrob Agents Chemother 2008, 52:3664-8.

FI000 Factor 6

Evaluated by Susan Swindells 17 May 2012

36. Diacon A, Dawson R, Van Niekerk C, Erondu N, Ginsberg A: Phase 2 Trial of a Novel 3-Drug Regimen for Both MDR and Drug Sensitive (DS) TB. [abstract] Presented at $5 \mathrm{Ist}$ Interscience Conference on Antimicrobial Agents and Chemotherapy: 17-20 September 20I I; Chicago, IL.

37. Nikonenko BV, Protopopova M, Samala R, Einck L, Nacy CA: Drug therapy of experimental tuberculosis (TB): improved outcome by combining SQI09, a new diamine antibiotic, with existing TB drugs. Antimicrob Agents Chemother 2007, 5 I:I563-5.

FI000 Factor 6

Evaluated by Susan Swindells 17 May 2012

38. Chen P, Gearhart J, Protopopova M, Einck L, Nacy CA: Synergistic interactions of SQI09, a new ethylene diamine, with frontline antitubercular drugs in vitro. J Antimicrob Chemother 2006, 58:332-7.

FI000 Factor 6

Evaluated by Susan Swindells 17 May 2012
39. Cynamon MH, Klemens SP, Sharpe CA, Chase S: Activities of several novel oxazolidinones against Mycobacterium tuberculosis in a murine model. Antimicrob Agents Chemother 1999, 43: ||89-9|.

40. Alcalá L, Ruiz-Serrano MJ, Pérez-Fernández Turégano C, de García Viedma D, Díaz-Infantes M, Marín-Arriaza M, Bouza E: In vitro activities of linezolid against clinical isolates of Mycobacterium tuberculosis that are susceptible or resistant to firstline antituberculous drugs. Antimicrob Agents Chemother 2003, 47:416-7.

41. Schecter GF, Scott C, True L, Raftery A, Flood J, Mase S: Linezolid in the treatment of multidrug-resistant tuberculosis. Clin Infect Dis 2010, 50:49-55.

FI000 Factor 8

Evaluated by Roman Kozlov and Sergey Yakushin 09 Mar 2010

42. Migliori GB, Eker B, Richardson MD, Sotgiu G, Zellweger J, Skrahina A, Ortmann J, Girardi E, Hoffmann H, Besozzi G, Bevilacqua N, Kirsten D, Centis $R$, Lange $C$ : A retrospective TBNET assessment of linezolid safety, tolerability and efficacy in multidrug-resistant tuberculosis. Eur Respir J 2009, 34:387-93.

43. Williams KN, Stover CK, Zhu T, Tasneen R, Tyagi S, Grosset JH, Nuermberger E: Promising antituberculosis activity of the oxazolidinone PNU-100480 relative to that of linezolid in a murine model. Antimicrob Agents Chemother 2009, 53:1314-9.

FI000 Factor 6

Evaluated by Susan Swindells 17 May 2012

44. Williams KN, Brickner SJ, Stover CK, Zhu T, Ogden A, Tasneen R, Tyagi S, Grosset JH, Nuermberger EL: Addition of PNU-I 00480 to first-line drugs shortens the time needed to cure murine tuberculosis. Am J Respir Crit Care Med 2009, I80:37I-6.

FI000 Factor 6

Evaluated by Susan Swindells 17 May 2012 